\title{
EFFECT OF ARONIA MELANOCARPA FRUIT JUICE ON RESERPINE-INDUCED HYPOKINESIA AND OXYDATIVE STRESS IN RATS
}

\author{
Miroslav Eftimov $^{1}$, Cvetomira Dobreva ${ }^{2}$, Deyana Velkova ${ }^{2}$, Stefka Valcheva-Kuzmanova ${ }^{1}$ \\ ${ }^{1}$ Department of Preclinical and Clinical Pharmacology, \\ Medical University - Varna \\ ${ }^{2} 5^{\text {th }}$ year student of medicine at Medical University - Varna
}

\begin{abstract}
INTRODUCTION: Reserpine can cause hypokinesia due to depletion of monoamine stores in the central nervous system.

PURPOSE: The aim of the present study was to investigate in the effects of Aronia melanocarpa fruit juice (AMFJ) on reserpine-induced hypokinesia and oxidative stress in male Wistar rats.

MATERIAL AND METHODS: Reserpine was applied as a single intraperitoneal dose of $6 \mathrm{mg} / \mathrm{kg}$ (as a $0.3 \%$ solution in $5 \%$ DMSO, $2 \mathrm{ml} / \mathrm{kg}$ ) and comparisons were made with the control group injected intraperitoneally with $5 \%$ DMSO $(2 \mathrm{ml} / \mathrm{kg})$. AMFJ was applied orally at doses of $2.5 \mathrm{ml} / \mathrm{kg}, 5 \mathrm{ml} / \mathrm{kg} \mathrm{and} 10 \mathrm{ml} / \mathrm{kg}$ three times (on the $0^{\text {th }}, 19^{\text {th }}$ and $23^{\text {rd }}$ hour) after reserpine administration while the control group received distilled water $(10 \mathrm{ml} / \mathrm{kg})$ at the same time points. The open field test (OFT) was used for investigation of locomotor activity. Oxidative stress was evaluated by the concentration of thiobarbituric acid reacting substances (TBARS) in rat brain.
\end{abstract}

RESULTS: Reserpine induced a significant reduction $(p<0.001)$ in both horizontal and vertical locomotor activity of rats. Brain TBARS in reserpine-treated animals were significantly higher $(p<0.05)$ in comparison with those of the control rats which indicated that reserpine induced oxidative stress. AMFJ caused a non-significant increase in locomotor activity of reserpine-treated rats. The concentration of TBARS in the brains of rats treated with AMFJ after reserpine did not differ significantly from the control level.

CONCLUSION: AMFJ prevented reserpine-induced oxidative stress and partly antagonized the effect of reserpine on locomotor activity of rats.

Keywords: Aronia melanocarpa, reserpine, behavior, oxidative stress, male rats

Address for correspondence:

Miroslav Tsonkov Eftimov

Department of Preclinical and Clinical Pharmacology,

Medical University Prof. Dr. Paraskev Stoyanov,

9002 Varna, 55 M. Drinov Str., Bulgaria;

e-mail:miroeftimov@yahoo.com

Received: November 4, 2014

Accepted: December 1, 2014

\section{INTRODUCTION}

Reserpine is an indole alkaloid derived from Rauwolfia plants. It is used as a drug in the treatment of hypertension and severe agitation in patients with mental disorders (e.g. schizofrenia) unable to tolerate phenothiazine derivatives or in those who also require antihypertensive medication. Reserpine inhibits the uptake of catecholamines and serotonin into 
storage vesicles leading to their depletion in the central and peripheral axon terminals. The depression of sympathetic nerve function results in a decreased heart rate and lowering of arterial blood pressure. Reserpine has also sedative and tranquilizing effects which are thought to be related to the depletion of catecholamines and 5-hydroxytryptamine in the brain. Systemic administration of reserpine causes depletion of brain catecholamines, resulting in akinesia in rodents (5). This movement disorder is due to the loss of dopamine storage capacity in intracellular nerve vesicles and is used as an animal model of Parkinson's disease. In this model, the motor syndrome is characterized by a decreased initiation and speed of voluntary movements, rigidity, and a hunched posture of the animals (6). Reserpine in a single dose induces oxidative stress in striatum and prefrontal cortex of rats and significantly elevates the levels of glutathione disulfide and nitric oxide (3).

Aronia melanocarpa Elliot (black chokeberry) is a woody shrub of the Rosaceae family, genus Aronia, native to the Eastern North America, now commonly planted in Eastern Europe. Aronia melanocar$p a$ fruits are used for human consumption as juice, syrup, jam, and wine. They are extremely rich in polyphenolic substances - proanthocyanidins, phenolic acids and flavonoids from the subclass of anthocyanins. Aronia melanocarpa polyphenols possess high antioxidant activity investigated using different well established assays $(13,22,23)$.

The aim of the present study was to investigate in the effects of Aronia melanocarpa fruit juice on reserpine-induced hypokinesia and oxidative stress in male Wistar rats.

\section{MATERIAL AND METHODS}

\section{Experimental substances}

AMFJ was produced from fresh Aronia melanocarpa Elliot fruits which were crushed and squeezed. The juice was filtered and stabilized using potassium sorbate $1.0 \mathrm{~g} / \mathrm{l}$. it was stored at $0{ }^{\circ} \mathrm{C}$ till the experiment.

Before the experiments, the contents of polyphenolic substances in the juice sample were determined. The phenolic substances in $100 \mathrm{ml}$ AMFJ were: total phenolics, $546.1 \mathrm{mg}$ as gallic acid equivalents, determined spectrophotometrically according to the Folin-Ciocalteu procedure (21); total proanthocyanidins, $312.3 \mathrm{mg}$, determined by gravimet- ric isolation according to the procedure described by Howell et al. (12); phenolic acids (chlorogenic $58.5 \mathrm{mg}$, neochlorogenic $-83.0 \mathrm{mg}$ ) determined by a high-performance liquid chromatography (HPLC) method at wavelength of $\lambda=280 \mathrm{~nm}$; anthocyanins (cyanidin-3-galactoside - $14.4 \mathrm{mg}$, cyanidin-3-arabinoside $-6.2 \mathrm{mg}$, cyanidin-3-xyloside $-1.2 \mathrm{mg}$ and cyanidin-3-glucoside $-0.4 \mathrm{mg}$ ) determined by HPLC at wavelength of $\lambda=520 \mathrm{~nm}$. Agilent 1220 HPLC system (Agilent Technology, Palo Alto, Ca) was used.

Reserpine (Sigma-Aldrich, Germany) was used in the experiment as a $0.3 \%$ solution in $5 \%$ dimethyl sulfoxide (DMSO).

\section{Animals}

Male Wistar rats with mean weight of $200 \pm 20 \mathrm{~g}$ were used. The animals were housed in plastic cages in a well ventilated room maintained at $22 \pm 1^{\circ} \mathrm{C}$ and on a 12/12 light/dark cycle. They had access to food and drinking water ad libitum. All procedures concerning animal treatment and experimentation were conducted in compliance with National and International laws and policies (EEC Council Directive 86/609).

\section{Experimental procedure}

The rats were divided in 5 groups of 9 animals: Control, Reserpine (R), R+AMFJ $2.5, \mathrm{R}+\mathrm{AMFJ}_{5}$ and $\mathrm{R}+\mathrm{AMFJ}_{10}$. Reserpine was applied as a single intraperitoneal dose of $6 \mathrm{mg} / \mathrm{kg}$ (as a $0.3 \%$ solution in $5 \%$ DMSO, $2 \mathrm{ml} / \mathrm{kg}$ ) to rats belonging to groups $\mathrm{R}$, $\mathrm{R}+\mathrm{AMFJ}_{2.5}, \mathrm{R}+\mathrm{AMFJ}_{5}$ and $\mathrm{R}+\mathrm{AMFJ}_{10}$ group while the control group was injected intraperitoneally with 5\% DMSO $(2 \mathrm{ml} / \mathrm{kg})$. AMFJ was applied orally through an orogastric cannula three times (on the $0^{\text {th }}, 19^{\text {th }}$ and $23^{\text {rd }}$ hour after reserpine administration) at doses of $2.5 \mathrm{ml} / \mathrm{kg}, 5 \mathrm{ml} / \mathrm{kg}$ and $10 \mathrm{ml} / \mathrm{kg}$ to groups R+AMFJ ${ }_{2.5}$, $\mathrm{R}+\mathrm{AMFJ}_{5}$ and $\mathrm{R}+\mathrm{AMFJ}_{10}$, respectively. The index in the group name indicates the AMFJ dose. The control group received distilled water $(10 \mathrm{ml} / \mathrm{kg})$ at the same time points. After the experiments, the rats were sacrificed under anesthesia with diethyl ether.

\section{Open field test (OFT)}

OFT is a common measure of exploratory behavior and general activity in rodents (10). It was performed for $5 \mathrm{~min}$ in an arena $(100 \times 100 \times 40 \mathrm{~cm})$ painted white except for $6 \mathrm{~mm}$ blue lines that divided the floor into 25 equal size $(20 \times 20 \mathrm{~cm})$ squares. Each animal was placed in the center of the uniform- 
Miroslav Eftimov, Cvetomira Dobreva, Deyana Velkova et al.

ly lit arena (60 W lamp) and its behavior was observed in silence for $5 \mathrm{~min}$. Behaviors recorded were: crossings (the number of lines crossed with the four paws) and rearings (the number of times the animal stood on its hind limbs).

\section{Thiobarbituric acid reactive substances}

Brains of rats were homogenized with ice-cold TRIS / $\mathrm{HCl}$ buffer at a weight/volume ratio of 1:10. The homogenate was centrifuged at $3000 \mathrm{x} g \mathrm{rpm}$ for $10 \mathrm{~min}$ and the resulting supernatant was used for biochemical analysis.

The content of the thiobarbituric acid reactive substances (TBARS) was used as a marker of oxidative stress in brain homogenates of the animals. TBARS were determined colorimetrically by the method of Ohkawa et al. without modifications (18) $(\lambda=532 \mathrm{~nm})$. The method measures spectrophotometrically the color produced by the reaction of thiobarbituric acid with the lipid peroxides. Aurius 2021 UV-VIS spectrophotometer (Cecil Instruments Ltd, UK) was used. TBARS were determined in $\mathrm{nmol} / \mathrm{g}$ tissue. Malondialdehyde, the major reactive aldehyde resulting from the peroxidation of biological membrane polyunsaturated fatty acids, was used as a standard.

\section{Statistical analysis}

Results are presented as mean \pm S.E.M. The data were analyzed by one-way ANOVA, followed by
Dunnett's multiple comparison post test to identify significant difference. All analyses were performed using GraphPad Prism statistical software. A level of $\mathrm{p}<0.05$ was considered significant.

\section{RESULTS}

\section{Open field test}

The results from the OFT are presented in Fig. 1. Reserpine induced a significant reduction $(\mathrm{p}<0.001)$ in both horizontal (2.8 \pm 1.1 for R group vs. $40.2 \pm 7.4$ for Control group) and vertical (1.0 \pm 0.5 for $\mathrm{R}$ group vs. $18.2 \pm 2.8$ for Control group) locomotor activity of rats. AMFJ caused a tendency to increase locomotor activity of reserpine-treated rats. The horizontal activity of AMFJ-treated rats was respectively: for $\mathrm{R}+\mathrm{AMFJ}_{2.5}$ group 11.6 \pm 6.3 (about 4 times higher than that of R group), for R+AMFJ ${ }_{5}$ group $3.2 \pm 1.4$ (almost equal to that of $\mathrm{R}$ group) and for $\mathrm{R}+\mathrm{AMFJ}_{10}$ group $11.3 \pm 5.5$ (about 4 times higher than that of $\mathrm{R}$ group) (Fig. 1A). The vertical movements were $4.3 \pm 2.1$ (4.3 times higher those of R group), $2.1 \pm 0.9$ (about 2 times higher those of $\mathrm{R}$ group) and 4.0 \pm 2.4 (4 times higher than those of $\mathrm{R}$ group) for $\mathrm{R}+\mathrm{AMFJ}_{2.5}, \mathrm{R}+\mathrm{AMFJ}_{5}$ and $\mathrm{R}+\mathrm{AMFJ}_{10}$ groups, respectively (Fig. 1B). These results showed that the locomotor activity of rats belonging to $\mathrm{R}+\mathrm{AMFJ}_{2.5}, \mathrm{R}+\mathrm{AMFJ}_{5}$ and $\mathrm{R}+\mathrm{AMFJ}_{10}$ groups was not significantly different in comparison with that of R group.
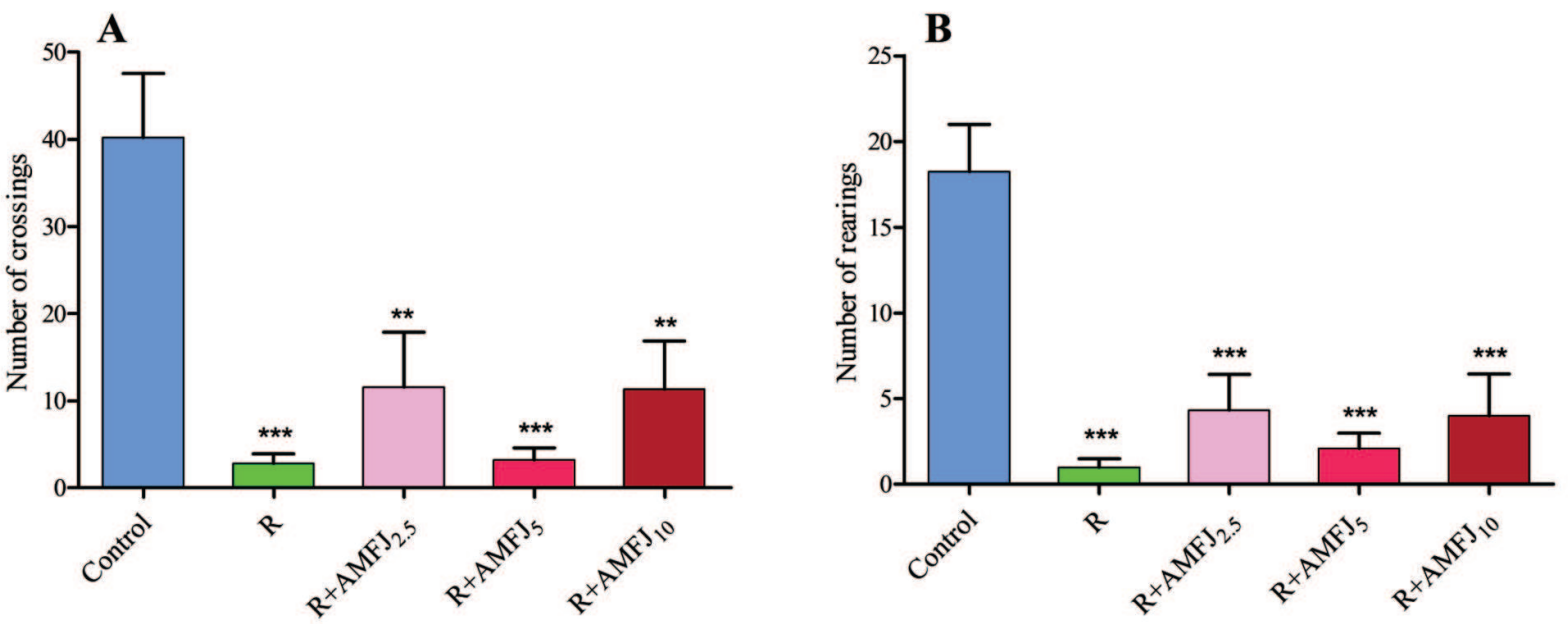

Fig. 1. Effect of Aronia melanocarpa fruit juice (AMFJ) at doses of 2.5, 5 and $10 \mathrm{ml} / \mathrm{kg}$ applied three times after reserpine $(R)$ administration on the horizontal (panel $A$ ) and vertical (panel B) locomotor activity of rats; ${ }^{* *} p<0,01{ }^{* * *} p<0,001$ vs. Control group 
Thiobarbituric acid reactive substances

Brain TBARS in animals from $\mathrm{R}$ group $(25.8 \pm 3.3 \mathrm{nmol} / \mathrm{g})$ were significantly (1.6 times) higher $(\mathrm{p}<0.05)$ in comparison with those of the control rats $(16.2 \pm 1.8 \mathrm{nmol} / \mathrm{g})$. The concentration of TBARS in the brains of rats treated with AMFJ before reserpine did not differ significantly from the control level. They were: $18.4 \pm 1.1 \mathrm{nmol} / \mathrm{g}$ for R+AMFJ ${ }_{2.5}(71 \%$ of the R group level); $20.6 \pm 1.7 \mathrm{nmol} / \mathrm{g}$ for R+AMFJ ( $80 \%$ of the R group level) and $20.5 \pm 4.0 \mathrm{nmol} / \mathrm{g}$ for $\left.\mathrm{R}+\mathrm{AMFJ}_{10}\right)(79 \%$ of the R group level) (Fig. 2). These values were non-significantly lower than the brain TBARS of animals belonging to R group.

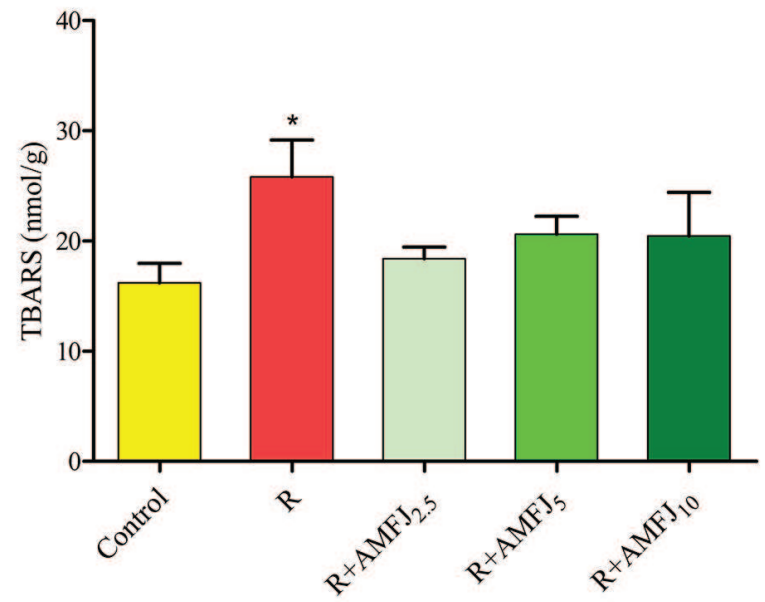

Fig. 2. Effect of Aronia melanocarpa fruit juice (AMFJ) at doses of 2.5, 5 and $10 \mathrm{ml} / \mathrm{kg}$ applied three times after reserpine $(R)$ administration on the levels of thiobarbituric acid reactive substances (TBARS) in the brains of rats; ${ }^{*} p<0,05$ vs. Control group

\section{DISCUSSION}

The main bioactive substances in AMFJ are polyphenols - proanthocyanidins, phenolic acids and flavonoids from the subclass of anthocyanins. The main AMFJ anthocyanins are glycosides of cyanidin. Recent studies have shown that polyphenols from berries can cross the blood-brain barrier $(1,14,19)$ and do accumulate in the brain following long-term consumption (24).

In this study, the OFT showed a significant decrease in locomotor activity of reserpine-treated animals. Reserpine-induced hypokinesia can be explained by the ability of the drug to block irreversibly the vesicular monoamine transporter (VMAT)
(11). This results in inability for norepinephrine, dopamine and 5-hydroxytriptamine (5-HT) to be deposited in their presynaptic vesicles as a consequence of which these mediators are metabolized by the enzymes monoamine oxidase (MAO) and catechol-Omethyltransferase (COMT). MAO exists in two similar molecular forms - MAO-A and MAO-B. MAO-A has a substrate preference for $5-\mathrm{HT}$ while both forms act on norepinephrine and dopamine. The depletion of norepinephrine and 5-HT in the central nervous system leads to depression while the depletion of dopamine leads to drug-induced parkinsonism characterized by hypokinesia, muscle rigidity and orofacial dyskinesia (2).

In rat brains, reserpine increased significantly the TBARS indicating that it induced oxidative stress in the treated animals. Dopamine VMAT blockade by reserpine promotes dopamine oxidative catabolism by MAO (9). As a result, dopamine-quinones and hydrogen peroxide are formed leading to oxidative stress $(4,17)$ in areas of the brain rich in monoamines such as the basal ganglia which are more vulnerable to free radical damage (15). The neuronal damage of the basal ganglia is associated with damage of voluntary movements (7).

AMFJ antagonized reserpine-induced oxidative stress as a result of which the levels TBARS in AMFJtreated rats did not differ from the control level. AMFJ is extremely rich in polyphenols which are powerful antioxidants (8-10) and this may explain the reduced oxidative stress. In this experiment, AMFJ also partly antagonized the reserpine-induced hypokinesia. At that moment, there is no reasonable explanation of the fact that the dose of $5 \mathrm{ml} / \mathrm{kg}$ had lower effect on locomotor activity in comparison with the effects of the doses $2.5 \mathrm{ml} / \mathrm{kg}$ and $10 \mathrm{ml} / \mathrm{kg}$. The antagonistic effect of AMFJ on reserpine-induced hypokinesia might be explained with a possible inhibitory effect of AMFJ polyphenols on the activity of MAO. This hypothesis is supported by data from experiments in vitro which have shown that the main anthocyanins in AMFJ (cyanidin and cyanidin-glycoside) inhibit MAO-A and MAO-B (8). There are similar data for green tea polyphenols as inhibitors of MAO enzyme activity leading to an increase of monoamines in rat C6 astrocyte cells (16). The results from this study are also in accordance with data from another experiment showing that the phenolic gallic acid 
Miroslav Eftimov, Cvetomira Dobreva, Deyana Velkova et al.

reduced the movement disorders (vacuous chewing movements) induced by reserpine (20).

\section{CONCLUSION}

The results from the present study demonstrate that AMFJ administered to rats after reserpine prevented reserpine-induced oxidative stress and partly antagonized the effect of reserpine on locomotor activity. This effect might be due to the activity of the polyphenolic ingredients of the juice acting as antioxidants and probably as inhibitors of MAO.

\section{ACKNOWLEDGEMENT}

We thank the Institute of Organic Chemistry with Centre of Phytochemistry - BAS, Laboratory of Biologically Active Substances, Plovdiv, for determining the contents of polyphenolic substances in the sample of AMFJ used in the experiment.

\section{REFERENCES}

1. Andres-Lacueva, C., B. Shukitt-Hale, R. L. Galli, O. Jauregui, R. M. Lamuela-Raventos, J. A. Joseph. Anthocyanins in aged blueberry-fed rats are found centrally and may enhance memory.- Nutr. Neurosci., 8, 2005, No 2, 111-120.

2. Barcelos, R. C. S., D. M. Benvegnú, N. Boufleur, C. Pase, A. L. M. Teixeira, P. C. Reckziegel, T. Emanuelli, J. O. B. T. Da Rocha, M. E. Bürger. Short Term Dietary Fish Oil Supplementation Improves Motor Deficiencies Related to Reserpine-Induced Parkinsonism in Rats.- Lipids, 46, 2010, No 2, 143-149.

3. Bilskaa, A., M. Dubiela, M. Sokolovska, E. LorencKocib. Alpha-lipoic acid differently affects the reserpine-induced oxidative stress in the striatum and prefrontal cortex of rat brain.- Neuroscience, 146, 2007, No 4, 1758-1771.

4. Burger, M., A. Alves, L. Callegari, F.R. Athayde, C.W. Nogueira, G. Zeni, J. B. T. Rocha. Ebselen attenuates reserpine-induced orofacial dyskinesia and oxidative stress in rat striatum.- Prog. NeuroPsychoph., 27, 2003, 135-140.

5. Carlsson, A., M. Lindquist, T. Magnusson. 3,4- Dihydroxyphenylalanine and 5-hydroxytryptophan as reserpine antagonists.- Nature (London), 180, 1957, 1200.

6. Colpaert, F. C. Pharmacological characteristics of tremor, rigidity and hypokinesia induced by reserpine in rat.- Neuropharmacology, 26, 1987, 1431-1440.
7. Dawson, L., A. Chadha, M. Megalou, S. Duty. The group II metabotropic glutamate receptor agonist, DCG-IV, alleviates akinesia following intranigral or intraventricular administration in the reserpinetreated rat.- Br. J. Pharmacol., 129, 2000, 541-546.

8. Dreiseitel, A., G. Korte, P. Schreier, A. Oehme, S. Locher, M. Domani, G. Hajak, P. G. Sand. Berry anthocyanins and their aglycons inhibit monoamine oxidases A and B.- Pharmacol. Res., 59, 2009, No 5, 306-311.

9. Fuentes, P., I. Paris, M. Nassif, P. Caviedes, S. Segura-Aguilar. Inhibition of VMAT-2 and DT-diaphorase induced cell death in a substantia nigra-derived cell line an experimental cell model for dopamine toxicity studies.- Chem. Res. Toxicol., 20, 2007, 776-783.

10. Gould, T. D., T. D. Dao, C. E. Kavacsics. The open field test.- In: Mood and anxiety related pheno types in mice. T. D. Gould, ed. New York, Humana Press, LLC, 2009, 1-2.

11. Henry, J. D. Scherman. Radioligands of the vesicular monoamine transporter and their use as markers of monoamine storage vesicles.- Biochem. Pharmacol., 38, 1989, No15, 2395-2404.

12. Howell A. B., J. D. Reed, C. G. Krueger, R. Winterbottom, D. G. Cunningham, M. Leahy. A-type cranberry proanthocyanidins and uropathogenic bacterial anti-adhesion activity.- Phytochemistry, 66, 2005, No 18, 2281-2291

13. Jakobek, L., M. Seruga, P. Krivak. The influence of interactions among phenolic compounds on the antiradical activity of chokeberries (Aronia melanocarpa).- Int. J. Food Sci. Nutr., 62, 2011, No 4, 345-352.

14. Janle, E. M., M. A. Lila, M. Grannan, L. Wood, A. Higgins, G. G. Yousef, R. B. Rogers, H. Kim, G. S. Jackson, L. Ho, C. M. Weaver. Pharmacokinetics and tissue distribution of ${ }^{14} \mathrm{C}$-labeled grape polyphenols in the periphery and the central nervous system following oral administration.- J. Med. Fd, 13, 2010, No 4, 926-933.

15. Lohr, J.B., R. Kuczenski, A.B. Niculescu. Oxidative mechanisms and tardive dyskinesia.- CNS Drugs, 17, 2003, No 1, 47-62.

16. Mazzio, E. A., N. Harris, K. F. Soliman. Food constituents attenuate monoamine oxidase activity and peroxide levels in C6 astrocyte cells.- Planta Med., 64, 1998, 603-606. 
17. Naidu, P.S., A. Singh, S.K. Kulkarni. Reversal of reserpine-induced orofacial dyskinesia and cognitive dysfunction by quercetin.- Pharmacology, 70, 2004, 59-67.

18. Ohkawa, H., N. Ohishi, K. Yagi. Assay for lipid peroxides in animal tissues by thiobarbituric acid reaction.- Anal. Biochem., 95, 1979, 351-358.

19. Rangel-Ordonez, L., M. Noldner, M. Schubert-Zsilavecz, M. Wurglics. Plasma levels and distribution of flavonoids in rat brain after single and repeated doses of standardized Ginkgo biloba Extract EGb 761.- Planta Med., 76, 2010, No 15, 1683-1690.

20. Reckziegel, P., L. R. Peroza, L. F. Schaffer, M. C. Ferrari, C. M. de Freitas, M. E. Bürger, R. Fachinetto. Gallic acid decreases vacuous chewing movements induced by reserpine in rats.- Pharmacol. Biochem. Behav., 104, 2013, 132-137.

21. Singleton, V., J. Rossi. Colorimetry of total phenolic with phosphomolibdiphosphotungstic acid reagents.- Am. J. Enol. Viticult., 16, 1965, 144-158.

22. Valcheva-Kuzmanova, S., B. Blagović, S. Valić. Electron spin resonance measurement of radical scavenging activity of Aronia melanocarpa fruit juice.- Phcog. Mag., 8, 2012; No 30, 171-174.

23. Valcheva-Kuzmanova, S., V. Gadjeva, D. Ivanova, A. Belcheva. Antioxidant activity of Aronia melanocarpa fruit juice in vitro.- Acta Aliment., 36, 2007, 425-428.

24. Willis, L. M., B. Shukitt-Hale, J. A. Joseph. Recent advances in berry supplementation and age-related cognitive decline (Note).- Curr. Opin. Clin. Nutr. Metab. Care, 12, 2009, No 1, 91-94. 